\title{
Histochemical Studies on the Gastric Cancer Cells
}

\author{
Yoshiaki OkUDA, Norihiko IwaI, Masahiko OHbayashi, \\ Hiroshi Sugrmoto, Shigetoshi Ohkawa, Sadaki Morita, \\ Yuzo Kanematsu and Akima Mryoshi. \\ The First Division, Department of Internal Medicine, Faculty of Medicine, \\ Kyoto University. (Director: Prof. GYOICHI WAKISAKA)
}

Enzymatic acitvity of the cancer cells is usually decreased in the degree than that of normal cells biochemically and histochemically as reported by Greenstein $^{1)}$, Rutenberg ${ }^{2)}$, Novikoff ${ }^{3)}$ and Wattenberg'). In contrast, Wattenberg stated that DPNH diaphorase (NADH dehydrogenase) activity was increased in large intestinal tumor.

In the previous histochemieal report ${ }^{5}$, the authors informed that this enzymatic activity was increased in some tumor cells. The present study deals with histochemical studies of gastric cancer cells.

\section{Materials and Methods}

Unfixed specimens of gastric cancer tissues resected surgically were cut at 10 microns in thickness in a cryostat maintained at $-15^{\circ} \mathrm{C}$. and the following enzymes were stained: Succinic dehydrogenase (Nachlas et al ${ }^{6}$.). NADH dehydrogenase (Nachlas et $\mathrm{al}^{7}$.), Glucose-6-phosphate dehydrogenase (Hess et $\mathrm{al}^{8}{ }^{\mathrm{j}}$.), $\beta$-Glucuronidase (Seligman et $\mathrm{al}^{9}{ }^{9}$.), Alkaline phosphatase (Gomori's cobalt method $\left.{ }^{(0)}\right)$, Acid phosphatase $\left(G^{\circ}\right.$ mori $\left.^{11}\right)$, Adenosine triphosphatase (ATP ase) (Wachstein \& Meisel $^{12)}$ and Leucine aminopeptidase (Nachlas et $\mathrm{al}^{13}$.). Formalin fixed tissues were stained with hematoxyline and eosin.

\section{Results}

In normal human stomach the parietal cells showed marked positive reaction for dehydrogenase systems, while the chief cells and surface epithelial cells showed slight activity as reported in the previous study (Fig. 1. 2.).

In the region of the intestinal metaplasia, higher activity of $\beta$-glucuronidase and NADH dehydrogenase was found as compared with that of succinic dehydrogenase and glucose-6-phosphate dehydrogenase. Strong activity of alkaline phosphatase and leucine aminopeptidase was also found in contrast to no activity of the same enzymes in normal gastric mucosa. Moderate positive reaction of acid phosphatase was also demonstrated in the same region, though this enzymatic activity was exclusively found in the chief cells of normal stomach.

In gastric cancer, on the other hand, NADH dehydrogenase, $\beta$-glucuronidase and acid phosphatase activity was increased in degree as compared with 
that of normal gastric mucosa, while the activity of succinic dehydrogenase and glucose-6-phosphate dehydrogenase was decreased in degree, showing faint-blue formazan granules scatterted throughout the cytoplasm (Fig. 3. 4.). No activity was found of the remaining enzymes.

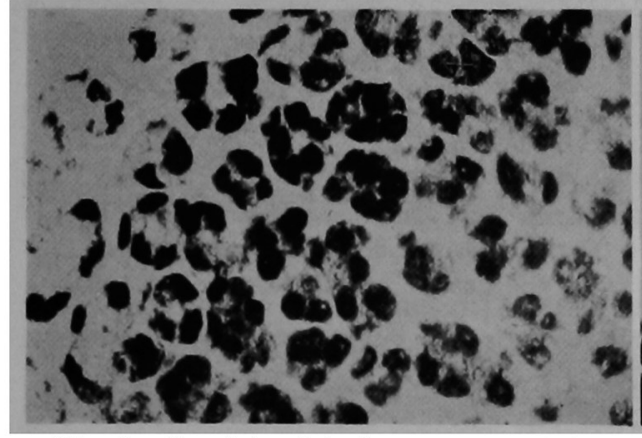

Fig. 1. Succinic dehydrogenase activity in the normal gastric mucosa $\times 100$

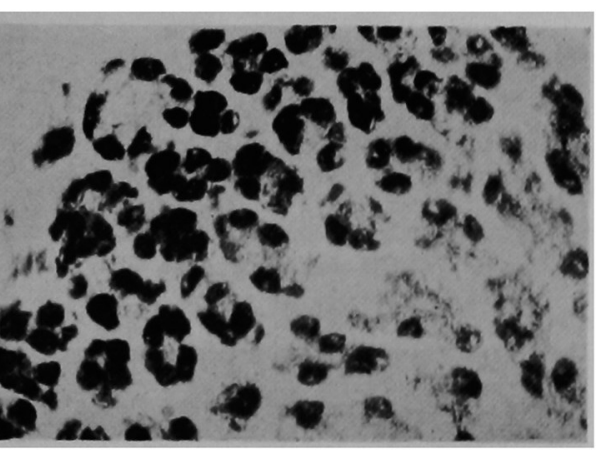

Fig. 2. NADH dehydrogenase activity in the normal gastric mucosa $\quad \times 100$

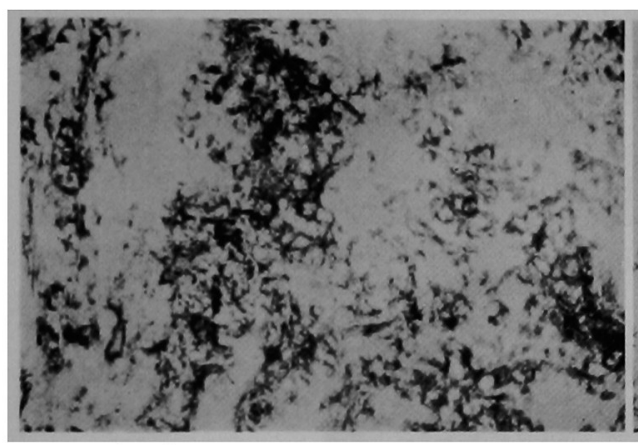

Fig. 3. Succinic dehydrogenase activity in the gastric cancer tissue $\times 100$

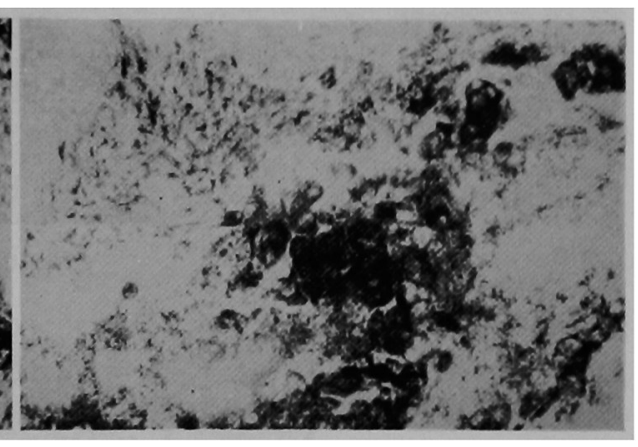

Fig. 4. Glucose-6-phosphate dehydrogenase activity in the gastric cancer tissue $\times 100$

Concerning with the relation between enzymatic activity and degree of differentiation of the cancer cells NADH dehydrogenase activity was increased in the undifferentiated cancer cells or in the region of irregular glandular structure of adenocarcinoma. The formazan granules of this enzyme were fine and increased in number, and the cytoplasm was diffusely stained in blue-blak color (Fig. 5. 6.). In moderately differentiated adenocarcinoma, however, the activity was lower than that of the undifferentiated cancer cells. Moreover, no activity of the same enzyme was found in the necrotic region of cancer tissue. Activity of $\boldsymbol{\beta}$-glucuronidase also was remarkable in the undifferentiated cancer cells, but slight in the differentiated cancer cells. However, in the latter group, the cancer cells accompanied by atypia and infiltrating characters revealed intense activity of $\beta$-glucuronidase (Fig. 7 . 8.). Activity of acid phosphatase was generally less marked than that of NADH dehydrogenase and $\beta$-glucuronidase. However, the activity of acid phosphatase was increased in degree in cancer cells spreading around the main cancerous regions, showing sharp demarcation of cancer tissue from 


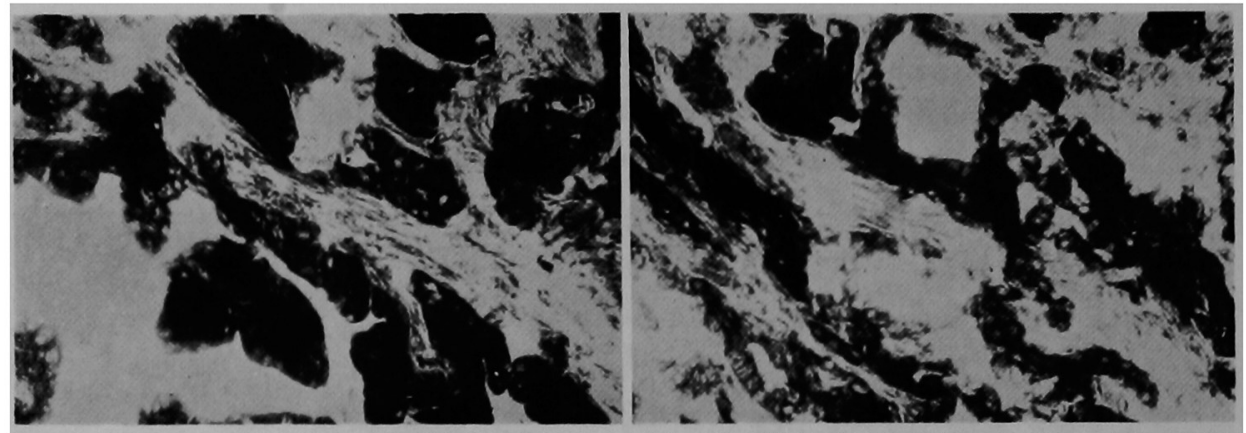

Fig. 5. NADH dehydrogenase activity in the gastric cancer tissue $\times 100$

Fig. 6. NADH dehydrogenase activity in the gastric cancer tissue $\quad \times 100$

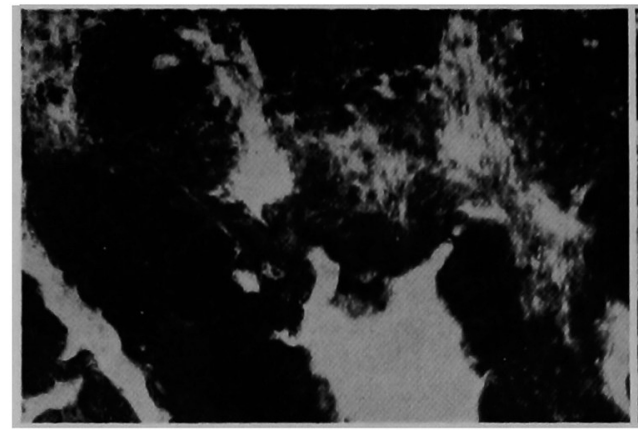

Fig. 7. $\beta$-Glucuronidase activity in the gastric cancer tissue $\times 100$

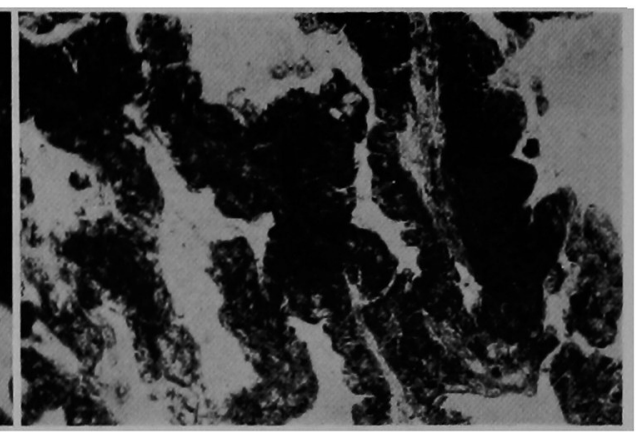

Fig. 8. $\beta$-Glucuronidase activity in the gastric cancer tissue

$\times 100$

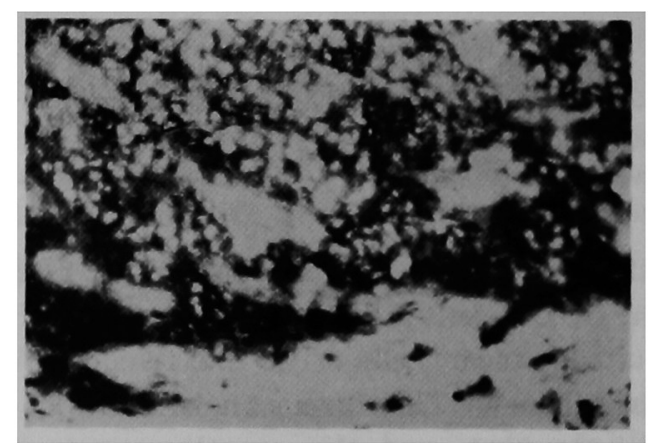

Fig. 9. Acid phosphtase activity in the gastric cancer tissue $\times 100$

the surrounding non-cancerous regions (Fig. 9). However, there was the tendency that activity of NADH dehydrogenase and $\beta$-glucuronidase was more specific for cancer cells than that of acid phosphatase. Alkaline phosphatase, ATP ase and leucine aminopeptidase were not detected in the cancer cells.

\section{Discussion}

Gastric cancer was classified pathologically into the following four types in the present study: 1. moderately differentiated columnar or cuboidal epithelial adenocarcinoma. 2. infiltrating solid carcinoma without glandular 
structures. 3. mucoid carcinoma with marked mucous degeneration. 4. undifferentiated carcinoma ("carcinoma simplex").

The present study that enzymatic activity of NADH dehydrogenase and $\boldsymbol{\beta}$-glucuronidase was increased in degree in the gastric cancer cells, while the remaining enzymes showed no reaction to them. Moreover, NADH dehydrogenase and $\beta$-glucuronidase activity was much higher in the undifferentiated carcinoma cells than in the differentiated one.

Wattenberg' reported that TPN diaphorase activity was found in both undifferentiated and differentiated cancer cells of the large intestine, but the activity was increased in the malignant polyp, in contrast to the decreased activity in the benign polyp.

Concerning with the difference of enzymatic activities in cancer cells and normal epithelial cells, Nachlas and Hannibal ${ }^{14)}$ stated that activity of TPN diaphorase was increased in degree in the former cells, though that of succinic dehydrogenase and $\alpha$-glycerophosphate dehydrogenase were decreased. Moreover, Fishman ${ }^{15-17}$ ) stated that the activity of $\beta$-glucuronidase closely related to the cell-multiplication and it was increased in degree in the cancer cells than in the normal cells.

Present investigation suggests that $\mathrm{NADH}$ dehydrogenase and $\beta$-glucuronidase activity is increased in the undifferentiated cancer cells, but succinic dehydrogenase and DPN linked dehydrogenase activity is decreased.

\section{Summary}

Histochemical studies of the gastric cancer cells showed the following results :

1. Alkaline phosphatase, leucine aminopeptidase and ATP ase activity was not found or slight in the gastric cancer cells.

2. Though activity of succinic dehydrogenase and glucose-6-phoshatase was increased in the differentiated cancer cells, it was decreased in the undifferentiated cancer cells.

3. NADH dehydrogenase and $\beta$-glucuronidase revealed much intense activity than the other enzymes. Moreover, activity of these enzymes varied corresponding to the degree of differentiation of the gastric cancer; undifferentiated cancer cells and infiltrating solid carcinoma without distinct glandular structures showed much intense activity than differentiated cancer cells.

\section{References}

1) Greenstein, J. P.: Adv. Enzymol. $3: 3151943$. and Seliman, A. M. : Cancer Research. $10: 113,1950$. search $17: 1010,1957$.

4) Wattenberg, L. W. : Am.
2) Rutenburg, A. M. Gofstein, R., 3) Novikoff, A. B. : Cancer Re-
Path. $35: 113,1959 . \quad$ 5) Mizutani, A., and Okuda, Y.: Proc. Japan Histochem. Assciation. $1: 74,1960.6$ 6) Nachlas, M. M., and Tsue, K.C.: J. Histochem. $5: 420,1957 . \quad 7)$ Nachlas, M. M., Walker, W. H., and Seligman, A. M. : J. Biophys. Biochem. Cytol. $4: 29,1958$. 8) Hess, R., Scalpelli D. C. and Pearse, A.G.E.: J. Biophys. Biochem. Cytol. $4: 753$, $1958 . \quad 9$ ) Seligman, A.M., Tsue, K.C.: J. Histochem. Cytochem. $2: 209,1954 . \quad 10)$ Gomori, G.: Microscopic 
Histochemistry, Principles and Practice. Univ. Chicago press. Chicago 1952 . 11) Gomori, G. : Stain Technol. $25: 81,1950$. 12) Wachstein, M., and Meisel, E. : Arch. Path. $65: 499$, 1958. 13) Nachlas, M. M., Crawford, D. T., and Seligman, A. M. : J. Histochem. Cytochem. 5 : 264, 1959. 14) Nachlas, M. M., and Hannibal, M. J. : Surg. Gynecol. Obstet. $112: 534$, 1961. 15) Fishman, W. H. : Adv. Enzymol. $16: 361,1955 . \quad 16)$ Fishman, W. H. et al. : Cancer Research. $7: 808,1947 . \quad 17)$ Fishman, W. H. et al. : J. Nat. Cancer Inst. $10: 1950$.

\title{
Histochemical Studies of Phosphatase in Cervical Carcinoma of the Uterus with Substrate of Several Kinds of Naphthol AS-phosphate
}

\author{
Yuzo Misonou and Yasushi Murase \\ Dept. of Obst. \& Gyn., School of Medicine Chiba Univ.
}

Varieties of Naphthol AS phosphate have been developed as substrate of phosphatase in the United States in recent years and were applied to histochemical demonstration of phosphatase activity by Burstone, Pearse et al. We mede histochemical studies of phosphatase activity in normal squamous epithelium, squamous carcinoma and adenocarcinoma of the uterine cervix with the following substrates. They were sodium $\alpha$-naphthyl phosphate ( $\mathrm{Na}$ $\alpha$-n. p.), calcium $\alpha$-naphthyl phosphate (Ca. $\alpha$-n. p.), 6-benozoyl-2-naphthyl phosphate (Na. 6-b. -2n. p,) Naphthol AS-AN phosphate (N. AS-AN. p.), Naphthol AS-BI phosphate (N. AS-BI p.), Napthol AS-CL phosphate (N. AS-CL p.), Naphthol AS-E phosphate (N. AS-E p.), Nathol AS-GR phosphate (N. AS-GR.), Naphthol AS-MX phosphate (N. AS-MX p.), and Naphthol AS-TR phosphate (N. AS-TR p).

With the azo-dye technique, Naphthanil Diazo Blue B (BB) was used as diazonium salt, and, in addition, naphthanil Diazo Red RC, Fast Blue RR and Fast Red Violet LB salts were also examined. Fifteen micron cryostat sections of the human uterine cervix were fixed in cold pure acetone in $4^{\circ} \mathrm{C}$ for 20 minutes and were histochemically stained for microscopic investigation. The staining procedures were shown in Table 1 . The histochemical distribution of acid phosphatase activity in normal squamous epithelium of the uterine ectocervix were remarkably characteristic according to the substrates employed.

The analysis of the distribution patterns of acid phosphatase activity lead to the classification of the substrates into 4 groups (Misonou-Murase's Classification) (Table 2). 